Vishniac, H. S. (1955). J. gen. Microbiol. 12, 455-463

\title{
The Nutritional Requirements of Isolates of Labyrinthula spp.
}

\author{
BY HELEN S. VISHNIAC \\ Department of Microbiology, Yale University, Nere Haven 11, Connecticut, U.S.A.
}

SUMMARY: The labyrinthula isolates of Watson will grow over a wide range of pH values in a medium of which the inorganic constituents reflect their marine origin. All are obligately marine, though the less exacting requirements of $L$. macrocystis var. atlantica suggest an estuarine habitat. Although only $L$. minuta var. atlantica requires an amino acid (L-leucine) as a growth factor, no isolate grew well on substrates other than amino acids. All require thiamine. Organic requirements may be obtained from host plants.

Labyrinthula Cienkowski (1863) is a genus of uncertain affinities, usually considered among the Myxomycetes. It is best known as including the probable causative organism of the wasting disease of eel grass, Zostera marina (Renn, 1935). Pure cultures of some members of the genus Labyrinthula have only recently been isolated by $\operatorname{Dr} \mathrm{S}$. W. Watson (to be published). The availability of pure cultures has made possible study of nutritional requirements. These studies were motivated not only by the specific economic importance of Labyrinthula spp. but by the interest which attaches to the nutrition of parasites and of marine micro-organisms in general. The latter because of the paucity of precise data on the requirements of an ecologically important group; the former because parasites may require growth factors available only in the intimate host-parasite relationship. Such parasites are uniquely useful biochemical tools.

Dr S. W. Watson has isolated three strains of Labyrinthula: L. vitellina var. pacifica (P), L. macrocystis var. atlantica (A), and L. minuta var. atlantica (M). $\boldsymbol{L}$. vitellina var. pacifica has a steroid growth factor requirement specifically unlike the steroid requirements of the few micro-organisms which share this characteristic (pleuropneumonia-like organisms, Trichomonas spp., Paramecium aurelia, Saccharomyces cerevisiae; for references see Vishniac \& Watson, 1953; Vishniac, 1955). This nutritional requirement for a steroid by L. vitellina var. pacifica, together with preliminary observations on the maintenance of all three isolates, was reported by Vishniac \& Watson (1953). The present paper reports the results of experiments on inorganic and organic nutritional requirements of the three labyrinthula isolates above mentioned.

\section{METHODS}

Cultures were maintained in screw-capped 'Kimble' culture tubes containing $5 \mathrm{ml}$. of the medium given in Table $\mathbf{1}$. The ingredients of this medium were completely dissolved in distilled water to one-half of the final volume, and 
the $\mathrm{pH}$ value adjusted to $7 \cdot 8-8 \cdot 0$ with potassium hydroxide, before the addition of agar and thiamine and dilution to final volume. Isolate $\mathbf{P}$ required in addition $0.5 \mathrm{mg}$. cholesterol $/ 100 \mathrm{ml}$; this cholesterol was added as an ethanolic solution to the still-boiling medium after solution of the agar. Gelatin hydrolysate was prepared as previously described (Vishniac \& Watson, 1953). The stock solution of iron used contained $\mathrm{FeSO}_{4} .7 \mathrm{H}_{2} \mathrm{O}, 24.9 \mathrm{mg} . / \mathrm{ml}$. $\left(\mathrm{Fe}^{++}, 5 \mathrm{mg} . / \mathrm{ml}\right.$.); EDTA, $30 \mathrm{mg} . / \mathrm{ml}$; $\left(\mathrm{NH}_{4}\right)_{2} \mathrm{CO}_{3}, 20 \mathrm{mg} . / \mathrm{ml}$.

\section{Table 1. Labyrinthula medium}

$100 \mathrm{ml}$. contains :

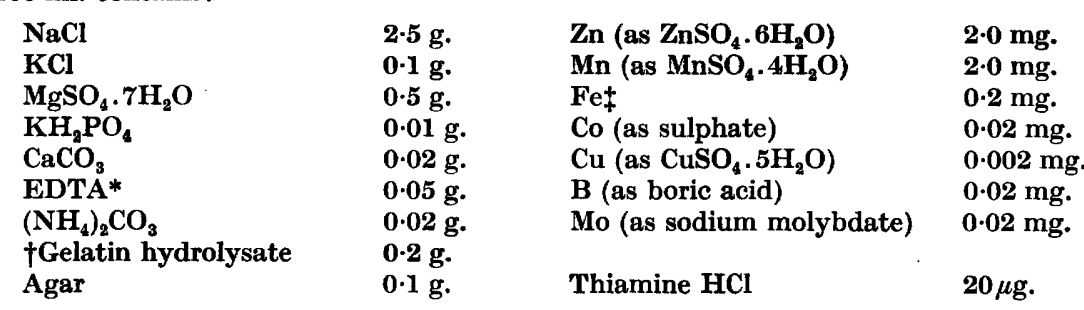

* $\mathbf{E D T A}=$ Ethylenediamine tetracetic acid='Versene', free acid ; Bersworth Chemical Co., Framingham, Mass. U.S.A.

$\dagger$ Prepared as by Vishniac \& Watson (1953).

¥ As stock solution containing: $\mathrm{FeSO}_{4} .7 \mathrm{H}_{2} \mathrm{O}, 24 \cdot 9 \mathrm{mg} . / \mathrm{ml}$. (Fe, $5.0 \mathrm{mg} . / \mathrm{ml}$ ); EDTA, $30 \mathrm{mg} . / \mathrm{ml}$; $\left(\mathrm{NH}_{4}\right)_{2} \mathrm{CO}_{3}, 20 \mathrm{mg} . / \mathrm{ml}$.

Experimental media were based on the formula given in Table 1, with the omission of the constituent being studied. Some of the experiments on inorganic nutrition were, however, conducted with a basal medium more nearly resembling that of Vishniac \& Watson (1953). Reagent grade chemicals were used. Experimental media were dispensed in $10 \mathrm{ml}$. lots in $25 \mathrm{ml}$. glasscapped Erlenmeyer flasks. After sterilization for $12 \mathrm{~min}$. at $120^{\circ}$ and inoculation, the flasks were sealed between Pyrex kitchen trays with transparent cellulose tape and incubated for 4-9 days at 20-21 ${ }^{\circ}$. Growth was followed by visual estimation until the end of the incubation period, when the optical densities of the cultures were read by a Klett-Summerson photoelectric colorimeter with no. 42 filter.

The media used contained $0 \cdot 1 \%(\mathrm{w} / \mathrm{v})$ Difco Bacto agar, an ingredient which contributes unknown chemical contaminants. The use of agar could be obviated by stirring the cultures mechanically on a shaking or rotating apparatus or by vigorous aeration. Such stirring is difficult to provide while simultaneously maintaining sterility, an all-glass culture assembly, and the temperature control considered necessary. The adequacy of the medium developed, in the absence of agar, was tested by growing each of the isolates with stirring by one or more of the methods mentioned.

All isolates grow equally well when incubated at $20^{\circ}$ or $25^{\circ}$ in tubes of stock medium for 5 days. Isolate $\mathbf{M}$ grows as well at $30^{\circ}$, while isolate $\mathbf{A}$ grows only slightly or not at all and isolate $\mathbf{P}$ not at all at this temperature. Dr S. W. Watson (personal communication) found that isolate $\mathbf{A}$ on serum sea water 
Nutritional requirements of isolates of Labyrinthula spp.

agar grew as well at $30^{\circ}$ as isolate $\mathbf{M}$. All isolates are killed by exposure to $36^{\circ}$ for 5 days. Since room temperature in our laboratory frequently exceeds $30^{\circ}$ during the summer and during the period when the heating system is in use, it seemed advisable to use a refrigerated incubator for these studies. The temperature $20-21^{\circ}$ was chosen because an incubator which could be controlled at this temperature was continuously available.

Preliminary experiments (and unpublished data of Dr Watson) indicated that the $\mathrm{pH}$ values of the medium could not be lowered below $7 \cdot 8$ without decreasing or abolishing growth. For this reason nearly all experiments were

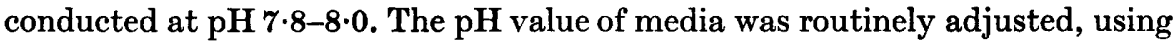
bromthymol blue and metacresol purple indicators. After the development of the medium given above, the $\mathrm{pH}$ response of all isolates was again investigated,

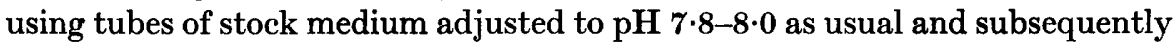
adjusted with sulphuric acid or potassium hydroxide (by using a Beckman model G pH meter) over the range $\mathrm{pH} \mathrm{3 \cdot 05-8 \cdot 52}$ in steps of approximately $0.5 \mathrm{pH}$ unit. In this experiment growth was limited by the appearance of a slight ( $\mathrm{pH} \mathrm{8.00)}$ or heavy ( $\mathrm{pH} \mathrm{8.2)} \mathrm{precipitate} \mathrm{in} \mathrm{the} \mathrm{medium} \mathrm{at} \mathrm{the} \mathrm{alkaline}$ end of the range and abolished by changes in the agar on autoclaving at the acid end ( $\mathrm{pH} 4.5$ and below). Slight, possibly not significant, maxima were observed: isolate $\mathrm{A}, \mathrm{pH} \mathrm{7.50}$; isolate $\mathrm{M}, \mathrm{pH} \mathrm{6.60}$; isolate $\mathrm{P}, \mathrm{pH} \mathrm{7.50}$. Growth tends to bring the medium to a reaction slightly above neutrality.

\section{RESULTS}

\section{Inorganic requirements}

All three isolates are obligately marine. The requirement for sodium chloride is illustrated in Fig. 1. No growth was made by isolates $\mathbf{P}$ and $\mathbf{M}$ when potassium chloride was supplied at $5.0 \mathrm{mg} . / 100 \mathrm{ml}$. or less. Potassium chloride at $50 \mathrm{mg} . / 100 \mathrm{ml}$. gave excellent growth, which was only slightly and variably improved by doubling this concentration. Potassium chloride at $50 \mathrm{mg} . / 100 \mathrm{ml}$. supplies to the medium c. $26 \mathrm{mg}$. potassium, which with the $c .3 \mathrm{mg}$. supplied as phosphate and c. $14 \mathrm{mg}$. used as hydroxide in adjusting the $\mathrm{pH}$ value in these experiments brings the total required concentration of potassium to c. $43 \mathrm{mg} . / 100 \mathrm{ml}$. In some experiments there were indications of a requirement for a constant ratio between sodium and potassium ions. In the narrow concentration ranges in which this occurred the obtainable differences in growth were, however, within the variation which normally occurred from experiment to experiment. It was therefore not considered worth while to pursue this line of investigation. The growth of isolate $\mathbf{A}$ was unaffected by the addition of potassium chloride to media lacking it.

Since preliminary experiments had indicated that magnesium and calcium could replace each other to a certain extent, experiments to determine the optimal concentrations of magnesium (weighed and used as $\mathrm{MgSO}_{4} .7 \mathrm{H}_{2} \mathrm{O}$ ) and calcium (weighed as $\mathrm{CaCO}_{3}$ and used as hydrochloric acid solution) ions were designed so as to test this point as well. No growth of isolates $\mathbf{M}$ and $\mathbf{P}$ occurred at $1 \cdot 0 \mathrm{mg}$. $\mathrm{Ca} / 100 \mathrm{ml}$. or less, or at $0 \cdot 1 \mathrm{~g} . \mathrm{MgSO}_{4} \cdot 7 \mathrm{H}_{2} \mathrm{O} / 100 \mathrm{ml}$. Isolate $\mathrm{A}$ grew, 
though poorly, at $0.05 \mathrm{~g}$. $\mathrm{MgSO}_{4} \cdot 7 \mathrm{H}_{2} \mathrm{O} / 100 \mathrm{ml}$. (in the presence of $8 \cdot 0 \mathrm{mg}$. $\mathrm{Ca} / 100 \mathrm{ml}$.), and in the absence of added calcium (in presence of $0 \cdot 4 \mathrm{~g}$. $\mathrm{MgSO}_{4} \cdot 7 \mathrm{H}_{2} \mathrm{O} / 100 \mathrm{ml}$.). Maximal growth of all strains occurred at $8-10 \mathrm{mg}$. $\mathrm{Ca} / 100 \mathrm{ml}$. and $0.5 \mathrm{~g} . \mathrm{MgSO}_{4} \cdot 7 \mathrm{H}_{2} \mathrm{O} / 100 \mathrm{ml}$. The calcium carbonate of the stock medium supplied $8.0 \mathrm{mg} . / 100 \mathrm{ml}$. of calcium ions. The data of these experiments are unsuitable for graphic presentation for the following reasons: the concentration of inorganic constituents of the medium affects rate as well as total amount of growth, and maximum growth is followed rapidly by

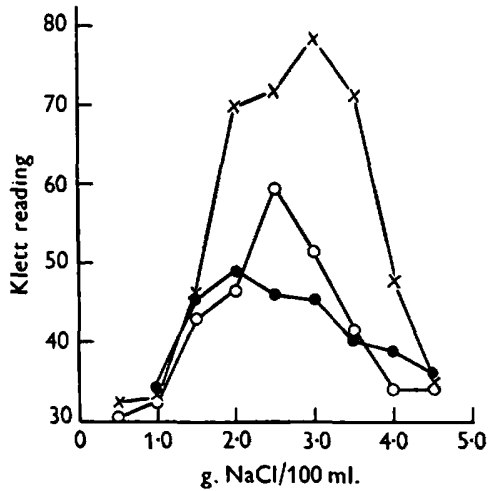

Fig. 1

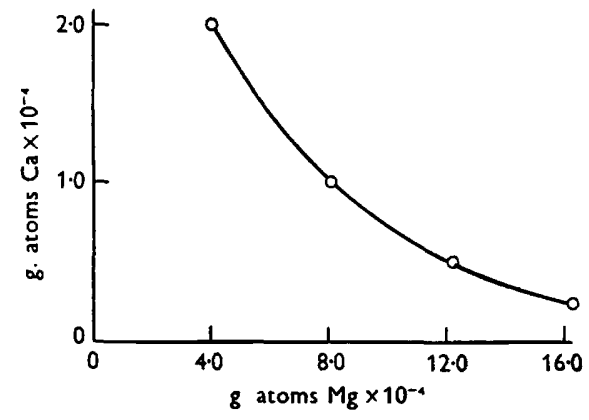

Fig. 2

Fig. 1. Growth response of isolates $A(O), M(x)$, and $P(O)$ to increasing concentrations of $\mathrm{NaCl}$ after incubation at $20^{\circ}$ for 5,4 and 5 days. Klett readings below 36 indicate no growth.

Fig. 2. Equivalents of $\mathrm{Mg}$ and $\mathrm{Ca}$ ions/100 ml. allowing growth of isolate $\mathrm{A}$ to Klett reading $70-71$ in 9 days.

autolysis. Since these experiments were read quantitatively only after 7 or 9 days of incubation, in order to follow the effects of the lower concentrations, flasks containing more nearly optimal concentrations were already beginning to undergo autolysis. The degree of replacement of magnesium and calcium by each other can, however, be seen in Fig. 2, in which the combinations of calcium and magnesium are plotted which had just resulted in growth to Klett reading 70-71 of isolate $A$ at the conclusion of the experiment (9 days). It will be noted that the replacement equivalence depends upon which of the variables is more limiting. Some of the replacement effect is undoubtedly due to the mass action of one or the other ion in displacing the other from the chelating agents present in the medium. The strongest of these chelating agents however (EDTA), is present at a concentration of only $3.05 \times 10^{-4} \mathrm{M}$ which is too little to bind all of the eligible metallic ions present. It was assumed that sulphate was not limiting at the lowest concentration of $\mathrm{MgSO}_{4} \cdot \mathbf{7} \mathrm{H}_{2} \mathrm{O}$ which permitted growth, since other metals were supplied as sulphates. In an experiment designed to test this assumption, $\mathrm{MgSO}_{4} \cdot 7 \mathrm{H}_{2} \mathrm{O}$ was replaced by an equivalent amount of magnesium as chloride and sodium sulphate. The use of $\mathrm{MgCl}_{2} \cdot 6 \mathrm{H}_{2} \mathrm{O}$ resulted in the formation of a precipitate and in poor or no growth whether or not sodium sulphate was present. 


\section{Nutritional requirements of isolates of Labyrinthula spp.}

When sodium chloride, potassium chloride, potassium phosphate, magnesium sulphate, and calcium carbonate were supplied in the amounts necessary for maximal growth, the addition of other inorganic nutrients (in the absence of EDTA) was superfluous. Such a medium develops the precipitate common to artificial sea waters. This precipitate is undesirable: it is a source of uncontrolled variation in the composition of the medium and in measuring growth spectrophotometrically. The precipitate does not form, and growth is markedly improved, when EDTA and the micronutrient elements are added as indicated in Table 1 . The formula given was designed for isolate $\mathbf{M}$, but gives good growth of isolates $\mathbf{A}$ and $\mathbf{P}$. Increase in no single micronutrient improved the growth of isolate $\mathbf{M}$. The inclusion of gelatin hydrolysate (or amino acids) in this medium, as well as the large amounts of salts required in any marine medium, make it unsuitable for the demonstration of micronutrient requirements. Nevertheless, in experiments with all three isolates in which the micronutrients were completely omitted from the stock medium, there was no growth. When the micronutrient elements were omitted singly, there was little or no growth in the absence of iron, a marked decrease in rate and amount of growth in the absence of manganese, and with isolate $\mathbf{P}$ a marked decrease in amount of growth in the absence of zinc.

\section{Vitamin requirements}

All isolates failed to survive continued subculture in media lacking thiamine. Fig. 3 illustrates the response of isolate $M$ to thiamine concentration after two passages through thiamineless media. The basal medium for this experiment contained an amino acid mixture instead of gelatin hydrolysate and only onehalf the amount of agar normally used. The addition of a mixture of watersoluble vitamins $\left(\mathbf{B}_{12}, p\right.$-aminobenzoic acid, nicotinic acid, calcium pantothenate, pyridoxamine. $\mathrm{HCl}$, biotin, folic acid) to media containing thiamine did not further improve growth of any isolate.

\section{Carbon and nitrogen requirements}

In preliminary experiments all isolates grew well with gelatin hydrolysate as carbon and nitrogen source but gave little indication of utilizing for growth any of the commonly used non-nitrogenous substrates, whether nitrogen was supplied as ammonium salts or by the addition of small amounts of amino acids. The following amino acids were therefore substituted singly (at $0.05 \mathrm{~g} . / 100 \mathrm{ml}$.) for the gelatin hydrolysate of the stock medium: DL-alanine, L-arginine. $\mathrm{HCl}$, (K) L-aspartic acid, (Na) L-glutamic acid, glycine, L-histidine.2HCl, DL-isoleucine, L-leucine, L-lysine. $\mathrm{HCl}$, DL-methionine, DL-phenylalanine, L-proline, DL-serine, DL-threonine, DL-tryptophan, L-tyrosine and DL-valine. The use of large inocula permitted growth on (in order of decreasing effectiveness): isolate $\mathbf{M}-\mathbf{L}-$ leucine, DL-alanine, L-proline, L-glutamic acid; isolate A-L-glutamic acid, L-aspartic acid, DL-alanine, L-proline; isolate $\mathbf{P}-\mathbf{L - g l u t a -}$ mic acid, L-proline, DL-alanine, L-arginine. $\mathrm{HCl}$. 
L-Histidine, DL-isoleucine, DL-methionine, DL-phenylalanine, L-tyrosine, and DL-valine in substrate concentration decreased or prevented growth of all isolates even in the presence of gelatin hydrolysate at $0.01 \mathrm{~g} .100 \mathrm{ml}$. The toxicity of isoleucine and valine, at concentrations of $1.0 \mathrm{mg} . / 100 \mathrm{ml}$. was annulled by combining them, as for certain mutants of Escherichia coli (Davis, 1950) and Neurospora sp. (Bonner, 1946). Glycine and DL-tryptophan were toxic for isolates $A$ and $M$; L-aspartic acid for isolate $P$; and DL-threonine for isolate A.

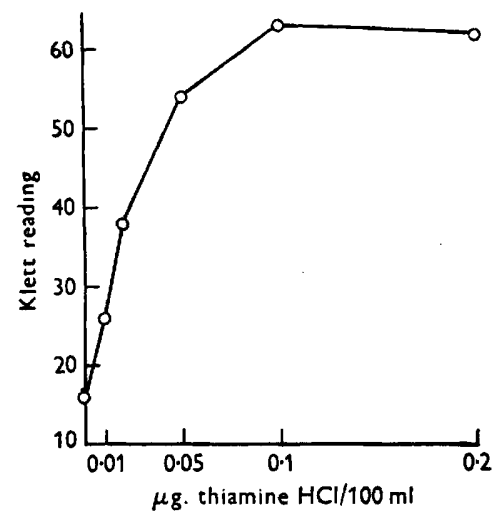

Fig. 3

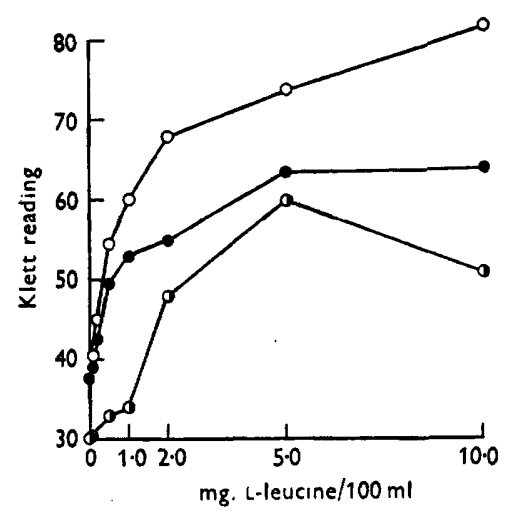

Fig. 4

Fig. 3. Growth response of isolate $M$ to increasing concentrations of thiamine. HCl after incubation for 7 days at $20^{\circ}$. No growth occurred in the absence of thiamine.

Fig. 4. Growth response of isolate $M$ to increasing concentrations of L-leucine after incubation at $20^{\circ}$ for 7 days. Substrates were $L$-proline ( $O$ ), DL-alanine (O), and NaHglutamate $(O), 0.05 \mathrm{~g} . / 100 \mathrm{ml}$. No growth occurred in the absence of leucine.

Each isolate was then serially subcultured in media containing (separately) the amino acids on which it had grown in this experiment. Subcultures were continued until growth ceased or for three to six transfers. Growth of isolate A reached a stable level on the second transfer: NaHglutamate and L-aspartic acid continued to be well utilized as substrates, though gelatin hydrolysate gave better growth at the same concentration, while DL-alanine and L-proline gave continuously culturable, but very poor, growth. Growth on L-aspartic acid was not significantly improved by the addition of $0.5-5.0 \mathrm{mg} . / 100 \mathrm{ml}$. of any other single amino acid. Isolate $P$ similarly continued to grow excellently on NaHglutamate, and as well or better on L-proline and DL-alanine as on an equal concentration of gelatin hydrolysate. Growth on L-arginine ceased on the second transfer. Growth of isolate $\mathbf{P}$ on DL-alanine or L-proline was not significantly improved by the addition of any other single amino acid at $0.5-5.0 \mathrm{mg} . / 100 \mathrm{ml}$.

Isolate $\mathbf{M}$, however, ceased to grow on the second transfer except on L-leucine, which supported very feeble growth. Although unsuitable as substrate, L-leucine (5.0 mg./100 ml.) alone of the 17 amino acids tested, restored growth of isolate $\mathrm{M}$ when DL-alanine, L-proline, or NaHglutamate was used 


\section{Nutritional requirements of isolates of Labyrinthula spp. 461}

as substrate. These cultures were carried through three transfers on each substrate in the presence of L-leucine. Growth was approximately equal, in all cultures, to that supported by a concentration of gelatin hydrolysate equal to that of the substrate amino acid $(0.05 \mathrm{~g} . / 100 \mathrm{ml}$.). The response of isolate $\mathrm{M}$ to L-leucine concentration after a single passage through leucineless media is seen in Fig. 4. Growth tended to be rather sparse and uneven in the experiments illustrated in Fig. 4 because of the sparse inoculum used. L-Leucine alone was inhibitory at $5.0 \mathrm{mg} . / 100 \mathrm{ml}$.; in the presence of other amino acids 10 or $20 \mathrm{mg} . / 100 \mathrm{ml}$. slowed growth.

The experiments just outlined clearly indicate that isolates $\mathbf{A}$ and $\mathbf{P}$, although only able to utilize amino acids as substrates for growth, do not require specific amino acids as growth factors. Glucose, ethanol, mannitol, $\mathrm{Na}$ lactate, $\mathrm{Na}$ acetate $\left(3 \mathrm{H}_{2} \mathrm{O}\right)$, glycerol, $\mathrm{Na}$ succinate $\left(6 \mathrm{H}_{2} \mathrm{O}\right)$, Na fumarate, $\mathrm{Na}$ malate, and $\mathrm{Na}$ citrate $\left(5 \frac{1}{2} \mathrm{H}_{2} \mathrm{O}\right)$ at $0 \cdot 1 \mathrm{~g} . / 100 \mathrm{ml}$. failed to support significant growth of isolates $\mathbf{A}$ and $\mathbf{P}$ in the presence of gelatin hydrolysate at $0.01 \mathrm{~g} . / 100 \mathrm{ml}$.

Since isolate $M$ is auxotrophic for L-leucine, further tests were made of a variety of compounds as substrates in the presence of L-leucine $(5 \cdot 0 \mathrm{mg} .100 \mathrm{ml}$.). Of amino acids not previously utilized as substrates, L-arginine. $\mathrm{HCl}$, (K) L-aspartic acid, and DL-phenylalanine supported equally modest growth at $0.05 \mathrm{~g} . / 100 \mathrm{ml}$. Soluble starch, sucrose, lactose, glucose, fructose, arabinose, xylose, ethanol, glycerol, mannitol, $\mathrm{Na}$ acetate $\left(3 \mathrm{H}_{2} \mathrm{O}\right), \mathrm{Na}$ lactate, $\mathrm{Na}$ fumarate, $\mathrm{Na}$ citrate $\left(5 \frac{1}{2} \mathrm{H}_{2} \mathrm{O}\right), \mathrm{Na}$ malate, $\mathrm{Na}$ succinate $\left(6 \mathrm{H}_{2} \mathrm{O}\right)$, and $\mathrm{Na}$ gluconate were also tested at $0.05 \mathrm{~g} . / 100 \mathrm{ml}$. Sugars were sterilized by filtration and added, as was ethanol, aseptically to sterile basal medium. Of these addenda, only glycerol supported significantly more growth than the basal medium alone. This poor and variable growth was not improved by the addition of Krebs cycle acids (succinic, fumaric, malic, or citric) to a medium in which the gelatin hydrolysate of Table 1 was replaced with glycerol $(0 \cdot 1 \mathrm{~g}$. $100 \mathrm{ml}$.) and gelatin hydrolysate $(0.01 \mathrm{~g} . / 100 \mathrm{ml})$ at either $\mathrm{pH} 7 \cdot 0$ or $\mathrm{pH} \mathrm{7.8}$. It is possible that the metal-binding properties of glycerol, rather than its energy content, are responsible for its effect on growth.

\section{DISCUSSION}

The ocean as an environment for micro-organisms has received little attention in comparison with fresh-water and terrestrial environments. The inorganic composition of the ocean, and its essential constancy, is well established. A series of studies (see Harvey, 1945, 1949) has indicated that the growth of phytoplankton in sea water is frequently limited by insufficient phosphate, nitrate, silicate, iron and manganese. But the relationship between those elements which are not limiting in sea water and the growth of marine microorganisms remains almost unknown. What are the elements in sea water which define the stenohaline niche? Cultural studies of marine micro-organisms have usually been carried out in sea water enriched with the known limiting elements (and perhaps a pinch of mud) or in artificial sea waters made up with more 
emphasis on the composition of natural sea water than the requirements of the micro-organisms concerned. The pioneering studies of Hutner (1948), using the inshore diatom Nitzschia closterium, indicated that considerable liberties could be taken with the composition of sea water in preparing a medium for this organism. In Table 2 the comparison is made between the concentrations of the major inorganic compounds of sea water (from Sverdrup, Johnson \& Fleming,1942), Hutner's medium for Nitzschia sp., and the labyrinthula medium

Table 2. A comparison of the major constituents of sea water and two

\begin{tabular}{|c|c|c|c|c|c|c|}
\hline \multirow{4}{*}{$\mathrm{Na}^{+}$} & \multicolumn{2}{|c|}{$\begin{array}{c}\left.\begin{array}{c}\text { Sea water } \\
(\mathrm{Cl}=19 \cdot 00 \%\end{array}\right)\end{array}$} & \multicolumn{2}{|c|}{ Labyrinthula medium } & \multicolumn{2}{|c|}{ Nitzschia medium } \\
\hline & mg./100 ml. & mg.-atoms/l. & mg./100 ml. & mg.-atoms/l. & mg. $/ 100 \mathrm{ml}$. & mg.-atoms/l. \\
\hline & $1055 \cdot 61$ & $470 \cdot 15$ & 984 & 428 & $86 \cdot 9$ & $37 \cdot 8$ \\
\hline & $127 \cdot 20$ & $\mathbf{5 3 \cdot 5 7}$ & $49 \cdot 3$ & $\mathbf{2 0 \cdot 3}$ & $24 \cdot 7$ & $10 \cdot 15$ \\
\hline $\mathrm{Ca}^{++}$ & 40.01 & $10 \cdot 24$ & $8 \cdot 0$ & $\mathbf{2} \cdot 0$ & $3 \cdot 5$ & 0.875 \\
\hline $\mathbf{K}^{+}$ & $38 \cdot 00$ & $9 \cdot 96$ & $55 \cdot 3$ & $14 \cdot 1$ & $7 \cdot 56$ & $\mathbf{2 \cdot 3}$ \\
\hline $\mathbf{S} \mathbf{r}^{++}$ & $1 \cdot 33$ & $0 \cdot 15$ & 0.0 & $0 \cdot 0$ & 0.0 & 0.0 \\
\hline $\mathrm{Cl}^{-}$ & $1897 \cdot 99$ & $548 \cdot 30$ & $1567 \cdot 7$ & $441 \cdot 4$ & $121 \cdot 4^{*}$ & $34 \cdot 2 *$ \\
\hline $\mathrm{SO}_{4}=$ & $264 \cdot 86$ & $38 \cdot 24$ & $170 \cdot 8$ & $20 \cdot 5$ & $97 \cdot 4 *$ & $10 \cdot 15 *$ \\
\hline $\mathrm{HCO}_{3}^{-}$ & $13 \cdot 97$ & $\mathbf{2 \cdot 3 4}$ & $6 \cdot 25 \dagger$ & $1 \cdot 04 \dagger$ & not det. & not det. \\
\hline $\mathrm{Br}^{-}$ & $6 \cdot 4,6$ & $0 \cdot 83$ & $0 \cdot 0$ & $0 \cdot 0$ & $0 \cdot 0$ & $0 \cdot 0$ \\
\hline $\mathrm{H}_{3} \mathrm{BO}_{3}$ & $\mathbf{2 \cdot 6 0}$ & $0 \cdot 43$ & $0 \cdot 114$ & $0 \cdot 00324$ & 0.286 & 0.00462 \\
\hline $\mathbf{F}^{-}$ & $0 \cdot 13$ & 0.07 & $0 \cdot 0$ & $0 \cdot 0$ & 0.0 & 0.0 \\
\hline
\end{tabular}

* The chloride and sulphate added as acid used to dissolve metals are not included in these calculations.

$\dagger$ Calculated from added ammonium carbonate. The bicarbonate content of the medium as used was not determined.

reported here. It is evident that the more exacting forms-the labyrinthulas -require not only a relatively narrow range of sodium chloride concentrations but also concentrations of magnesium, calcium and potassium which are of the same order of magnitude as the concentrations of these elements in the ocean. Using such requirements as criteria of stenohalinity, isolates $\mathbf{M}$ and $\mathbf{P}$ are most stenohaline and would be expected to occur primarily in open ocean or inshore areas of little land drainage. Isolate $\mathbf{A}$, although its range of sodium chloride tolerance is the same as that of isolates $\mathbf{M}$ and $\mathbf{P}$, is less stenohaline; the optimum sodium chloride is lower, magnesium and calcium requirements are less rigid, and the high potassium requirement is absent. This strain would be expected to predominate in estuarine habitats. The ecological studies which would provide a test of the applicability of such laboratory findings have not, however, been made. Moreover, the unpublished data of Dr S. W. Watson indicate that both isolates $\mathbf{A}$ and $\mathbf{M}$ grew as well on serum sea water agar made with $50 \%(\mathrm{v} / \mathrm{v})$ sea water, as when $100 \%$ sea water was used.

Since the labyrinthulas are heterotrophic, one cannot consider the small and ill-defined organic content of the ocean to be the source of their organic requirements; thiamine, steroids and amino acids are readily available from host plants. The host plants serve other, less obvious, functions as well, 
Nutritional requirements of isolates of Labyrinthula spp. 463

providing the physical support necessary for motility of Labyrinthula spp. and providing oxygen. The isolates of Labyrinthula used in these studies were so highly aerobic that they could surely not compete for food with the bacterial flora of the ocean except in association with actively photosynthesizing organisms. They were unable, for example, to flourish under a 7-8 mm. stationary layer of liquid medium.

It is a pleasure to acknowledge my indebtedness to Dr S. W. Watson for the isolates used in this study and for permission to use his unpublished data, to $\mathrm{Dr} \mathbf{S}$. H. Hutner of Haskins Laboratories, where these studies were begun, and to $\mathrm{Mr} \mathrm{S}$. E. Mills, for expert technical assistance. These studies were aided by a grant from the Eugene Higgins Fund and by a contract between the Office of Naval Research, Department of the Navy, and Yale University, NR 135-241.

\section{REFERENCES}

Bonner, D. (1946). Biochemical mutations in Neurospora. Cold Spr. Harb. Symp. quant. Biol. 11, 14.

Cienkowski, L. (1863). Utber den Bau und die Entwicklung der Labyrinthuleen. Arch. mikr. Anat. 3, 274.

Davis, B. D. (1950). Studies on nutritionally deficient bacterial mutants isolated by means of penicillin. Experientia, 6,41 .

Harvey, H. W. (1945). Recent Advances in the Chemistry and Biology of Sea Water. Cambridge: University Press.

HARvey, H. W. (1949). Manganese and the growth of phytoplankton. J. Mar. biol. Ass. U.K., N.S. 26, 562.

Hutner, S. H. (1948). Essentiality of constituents of sea water for growth of a marine diatom. Trans. N.Y. Acad. Sci. 10, 136.

RENN, C. E. (1935). A mycetozoan parasite of Zostera marina. Nature, Lond. 135, 544.

Sverdrup, H. V., Johnson, M. W. \& Fleming, R. H. (1942). The Oceans. New York: Prentice-Hall Inc.

VishnIAC, H.S. (1955). The activity of steroids as growth factors for a Labyrinthula sp. J. gen. Microbiol. 12, 464.

Vishniac, H. S. \& Watson, S. W. (1953). The steroid requirements of Labyrinthula vitellina var. pacifica. J. gen. Microbiol. 8, 248. 